\title{
Hybrid DC-AC homes with roof top solar power
}

\author{
Madhu M. $C^{I^{*}}$, K. Badari Narayana ${ }^{2}$, J. Krishna Kishore ${ }^{3}$ \\ 1 Department of Mechanical Engineering, BMS Institute of Technology and Management, \\ Bengaluru, India \\ 2 Department of Mechanical Engineering, Ramaiah Institute of Technology, Bengaluru, India \\ ${ }^{3}$ U R Rao Satellite Centre, Bengaluru, India
}

\begin{abstract}
The paper investigates the feasibility of a hybrid DC-AC home with roof top solar power. In recent times, roof top solar power has become popular for residential homes. Generally, the power obtained from roof-top solar panels is converted to $\mathrm{AC}$ with a power control unit and routed to the existing wiring network of the houses designed essentially to support the Electric Utilities which deliver AC power. Solar power with DC bus routing power to various sub-units and Brushless DC (BLDC) motor-based systems have been successfully flown in satellites for decades. The study presents the possibility of having a dedicated DC bus $(24 \mathrm{~V} / 48 \mathrm{~V})$ in the home connected directly to roof-top solar panels along with the traditional wiring network to support AC power (220-230V) from Electric Utilities. The recent success of the BLDC based home appliances further highlights the potential. This will also help to benefit from higher efficiency due to BLDC and avoid the conversion losses as home appliances that can run on DC power are presently available. It is now possible to have an independent local Roof Top solar power-based DC home-grid to support lighting circuit and homeappliances that operate on DC power. The existing wiring network for $\mathrm{AC}$ can continue to support high power equipment like motors, boilers, washing machines etc., It will also simplify the power control unit as the traditional inverter portion is avoided. Thus, the proposed hybrid DC-AC home needs be viewed in terms of an overall green approach which will be a paradigm shift for energy efficiency and lower carbon footprint. It has the potential to boost the sale of DC home appliances.
\end{abstract}

Key words: DC power, electric utilities, green home, solar vehicle to home

\section{INTRODUCTION}

In this article, the focus is to highlight the need to promote hybrid DC-AC homes with rooftop solar power. Residential homes across the nation have become significant consumers of electric power due to a modern lifestyle driven by urbanization. A typical urban home requires an average of 2 to $3 \mathrm{KW}$ per family. The demand runs into Giga watts of power across the nation due to lakhs of All Electric Homes. India's solar potential of 6 Billion GWh as shown in Figure 1. can be used to generate roof-top solar power recognizing the crucial 
role of solar power, the National Solar Mission (NSM) was launched in 2010, by the Gov. of India with the aim of installing $100 \mathrm{GWs}$ solar power by 2022.

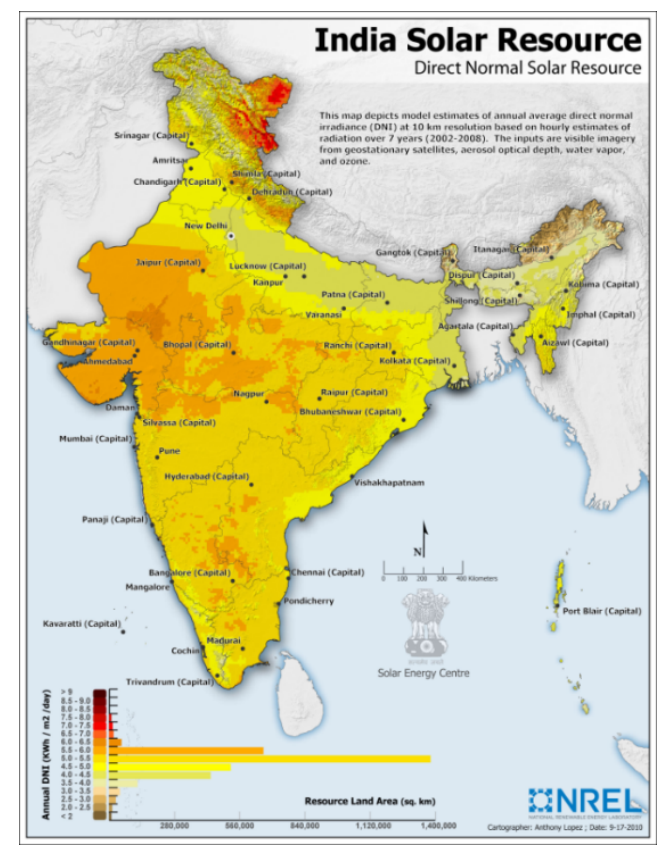

Figure 1: India's Solar Potential (National Resource Energy Laboratory)

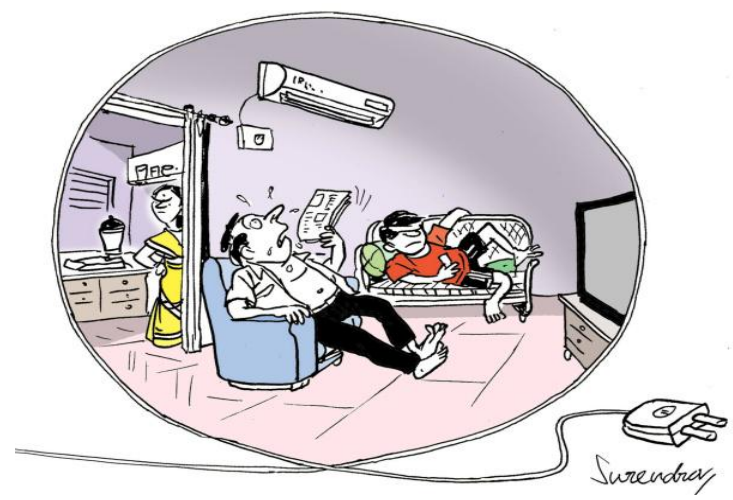

Figure 2: Typical All Electric Home (AEH)

The power consumption in urban areas shows the socio-economic situation and the plight of rural areas. Roof-Top solar power supported Hybrid DC-AC homes has the potential to liberate Giga Watts of Power in Urban Areas from the grid which can be used for the development of rural areas and Smart Villages to improve their quality of life. This can possibly reduce the pressure on the already loaded urban infrastructure by reversing the migration from rural areas to urban areas. Figure 2. Represents a typical AEH home. Poor availability of electricity, education, employment, and health care due to lack of development in rural areas has led to migration from rural to urban areas. Hence, even small, and medium 
enterprises are located in urban areas due to poor infrastructure and electricity access in rural areas. Mass migration to urban cities has invited younger people to find jobs and support themselves and support family and elders back home. Hence the labor cost and overall cost of living has increased even in urban areas. The recent pandemic COVID-19 has shown the need and urgency for distributed development across rural areas so that migration can be minimized. As the quality of life improves, the relentless migration to urban areas can be slowed down to improve social security and better health care.

Section 2 discusses the emerging trends, while in Section 3 discusses a typical hybrid DC$\mathrm{AC}$ home and Section 4 gives the conclusion.

\section{Emerging Trends}

Roof top solar power has become popular for residential homes. The possibility of synergy exists between roof-top solar power and DC bus operated home appliances. Historically, these home appliances used single-phase AC induction motors. A new era has emerged, where DC power-based home appliances are available today in the consumer market due to BLDC. Most electrical devices even when supplied by AC operate on DC internally. The DC operated appliances avoid the rectifier electronics, thereby making devices simpler and more reliable with reduced power loss. For example, LED- lamps on DC supply can be realized with minimum components. Rooftop solar panels are a Photovoltaic source, and they generate DC power and can be used for DC based LED lamps, DC fans which will definitely reduce the electrical consumption from the grid, thereby saving electrical energy. This saved energy may be used for Industrial and agricultural sectors.

Figure 3 shows the typical home appliances which have traditionally operated on AC power. However, it is now possible to have DC power-based home appliances connected directly to DC bus derived from roof-top solar panels.

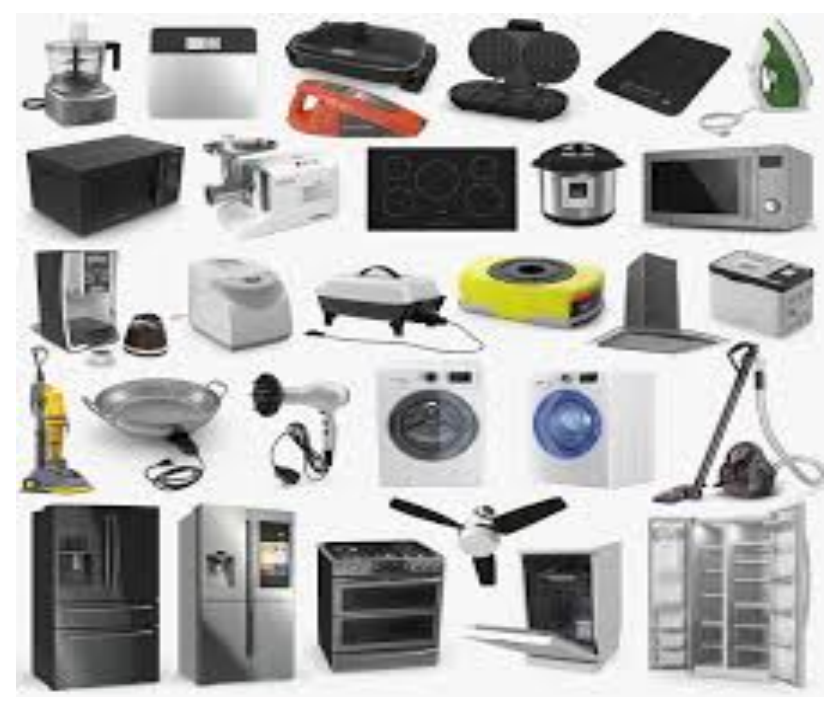

Figure 3: Home Appliances

Figure 4 depicts a BLDC home appliance and Figure 5 shows how a DC grid works better than $\mathrm{AC}$ (and may reduce losses up to $5 \%$ ). Figure 6 shows a DC fan which can replace AC 
fans while Figure 7. gives a comparison between AC motor and BLDC based applications $[11,12]$.

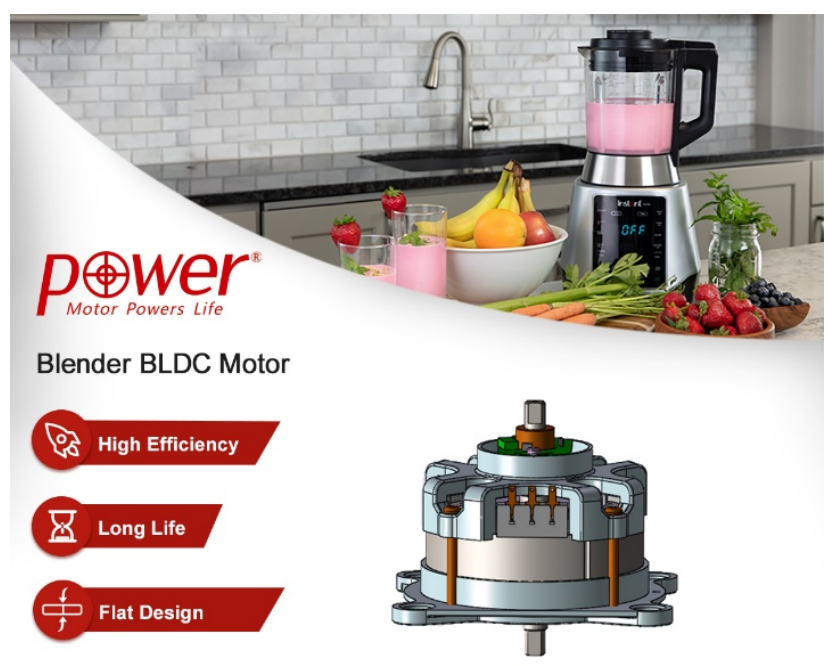

Figure 4: BLDC based home appliance - Mixie

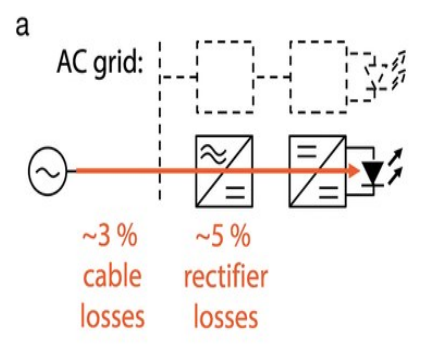

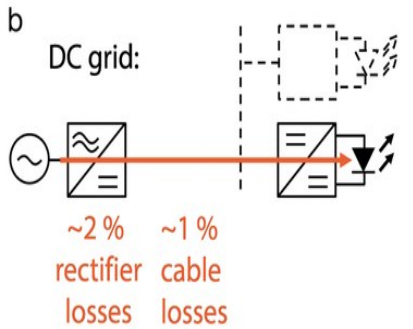

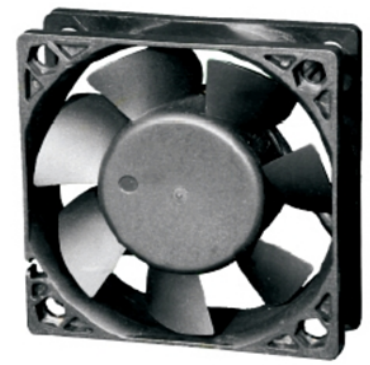

Figure 6: DC fan

Figure 5: AC and DC grid comparison 


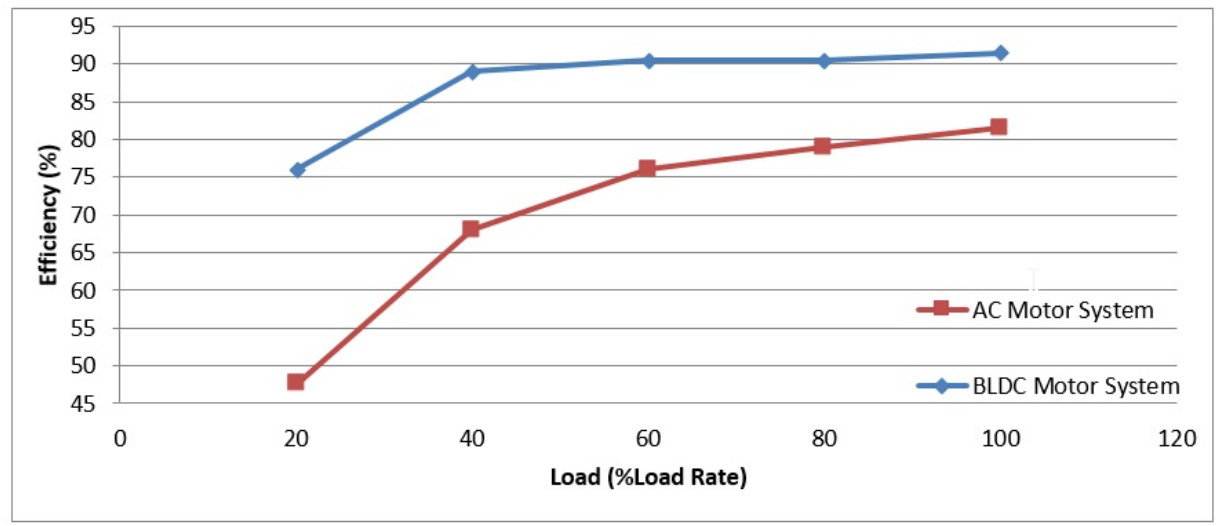

Figure 7: Efficiency comparison

Since many appliances work on DC current, DC grids are becoming attractive in recent days. LED Lamps especially are the best example to be used in houses. These work on DC current and are examples to save power. During AC-DC conversion, the losses are around 5\% for LED lamps, this loss of 5\% does not occur if DC is used. DC fans consume less power than AC fans. BLDC motors have advantages such as reduced electricity consumption which gives advantage of longer backup on Inverters (even on Solar) and improved reliability. Noise reduction and longer lifetime. AC bus is also influenced by power factor aspects which is not present if DC bus rail is used to power home appliances. Many electrical appliances operate internally on DC power. Computers and electronic gadgets which are common in today's homes work on DC power.

LEDs are becoming popular in today's houses. They also contribute to the energy savings. An LED light has $40 \%$ of its components for AC-DC conversion. Which will make them simple to manufacture at lower cost and more reliable. DC bus at home is dependent on factors like conversion losses, electrical energy storage, length of the electric cables across the home and power consumption of the electrical appliances. The Figure 8 shows the components in an electronic circuit for AC supply.

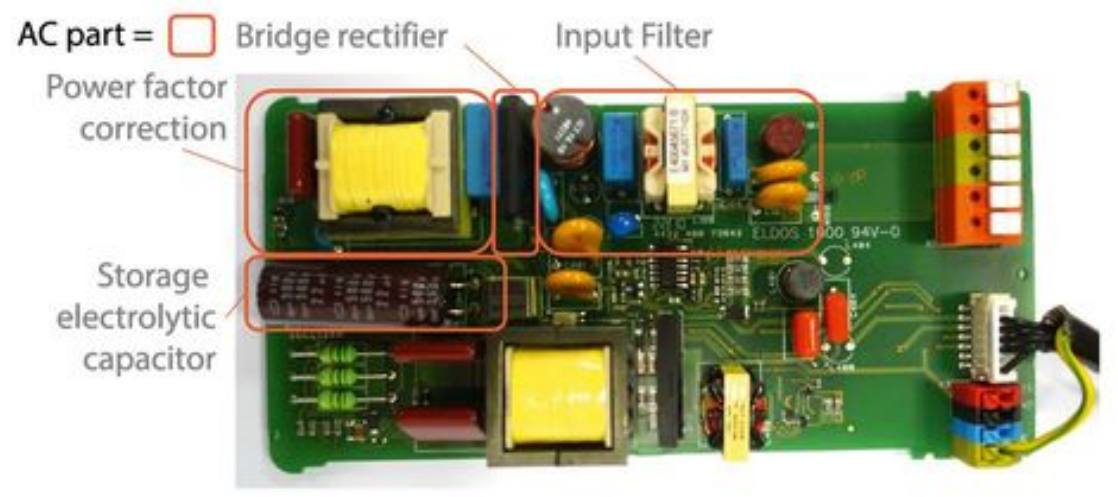

Figure 8: Components of an electronic circuit using AC power (11)

Drive motors of household appliances can be divided into AC and DC motors. Considerable progress in brushless DC motor (BLDC) has made household appliances possible like the 
blender, juicer, coffee machine, tea machine, electric knife, eggbeater, rice cooker, food processor, grain grinder, straight mixer, and electric cutter. The same can be extended to floor cleaning devices also. The concept of low-carbon energy-saving products is vital to protect the environment. The brushless DC motor-based home appliances can help to meet the requirements of energy saving and low carbon footprint.

Rather than focusing on a dedicated DC home or AC home, a hybrid AC-DC home is proposed. A home DC grid can be set up for low power devices such as LED-lights, laptops, and TV, while a separate AC grid is used for high power devices. This approach can be adopted for homes and small offices.

\section{Proposed Hybrid DC-AC home}

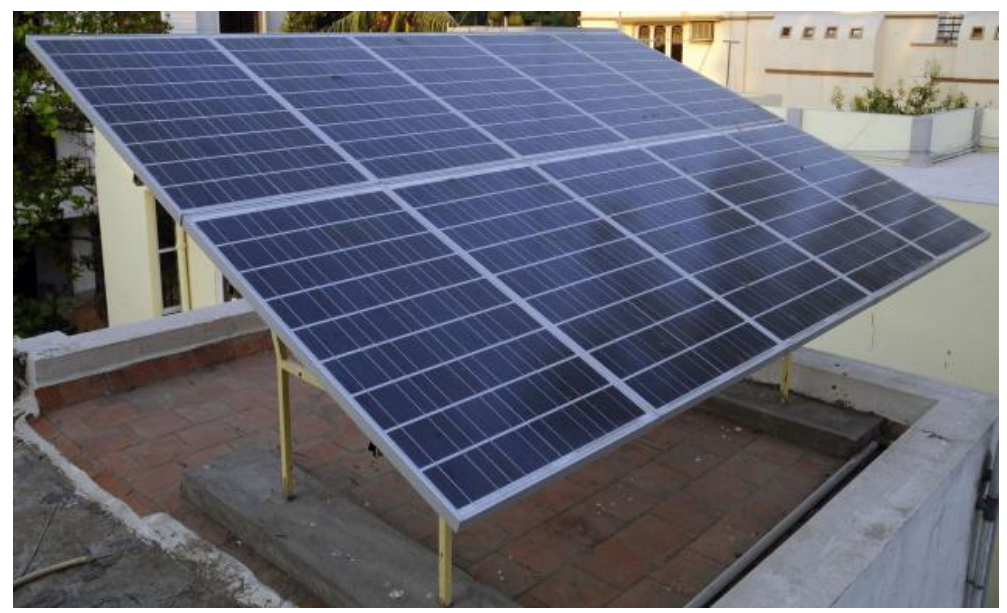

Figure 9: Roof top Solar Power heater and plant

In a hybrid DC-AC Bus home, provision needs to be made for a DC bus from Roof Top Solar Power and AC bus from the Electric Utility. Thus, electricity used in residential homes can be divided into two categories: DC bus based circuitry (light, TVs, fans etc.,) and motor drive (refrigerator, washing machine, air conditioner, fan, vacuum cleaner, etc.), and give scope for future design of green buildings. Figure 9 shows roof top solar panels which can be used to generate 1 to $2 \mathrm{KW}$ for the DC bus in a typical 2 Bedroom home as shown in Figure A1. The DC power generated from the solar panels can be supplied at $24 \mathrm{~V} / 48 \mathrm{~V}$. The total load coming on the house can now be distributed between DC and AC buses. The DC power is distributed to all the power points in the house through cables. As many DC home appliances with same functionality are now available, it is possible to replace certain AC appliances like lamps, LED bulbs, fan etc., in the home. A DC bus rail can be used to avoid the traditional inverter/converter circuitry and losses. This can potentially help to reduce electrical energy drawn from the electrical grid which can be diverted to industry / agriculture usage etc.,

The future use of DC is also seen in the charging of Electric vehicles. All hybrid DC-AC homes can also have the advantage to receive energy from battery of Electric vehicles as shown in Figure 10 as Back-Up option in case of Emergency. 


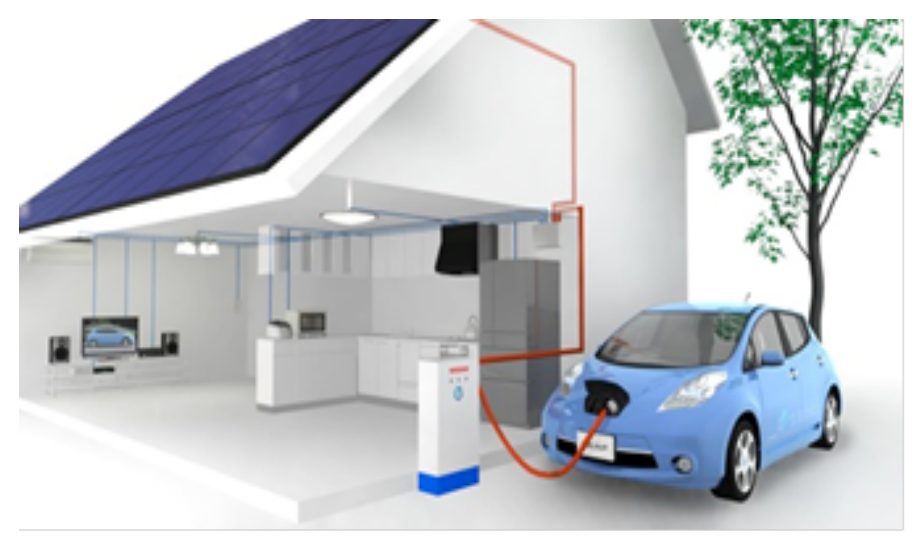

Figure 10: Charging an electric vehicle in a DC home

\section{Socio-economic benefits of Hybrid DC-AC}

- Generation of Gigawatts of roof top Solar Power

- Saves GWs of Power due to conversion losses due to DC home appliances and by avoiding Transmission \& Delivery due to local generation and consumption.

- Increased strategic security due to local power generation unlike central power generation

- Enhanced tariffs in industry power will help to increase revenues of electricity boards.

- Saving of precious water used in thermal plants for power generation which can be used for agriculture to sustain food security and supplying drinking water to dry areas.

- Land acquisitions can be avoided as Roof-Top area is available...

- Human cost is avoided as there is no displacement and rehabilitation of people to alternate locations due to land acquisition as in case of Hydel / Thermal / Nuclear Projects etc.,

- Carbon footprint can be reduced per home

- High Job potential can be generated in Solar Sector / DC home appliance sector

○ Boost to Manufacturing sector for DC Home appliances 


\section{Conclusion}

The aim of the study is to present the feasibility of hybrid DC-AC home supported with roof-top solar power as BLDC based home appliances is possible. A typical room layout for a 2 or 3 BHK was taken to highlight how much load can be transferred to the DC bus. A home DC-grid at $24 \mathrm{~V}$ or $48 \mathrm{~V}$ can be considered. The conversion losses can be avoided. However, care needs to be taken w.r.t cabling network and associated losses. It has the potential to boost home DC appliances so that the power that is saved in residential homes can be diverted to industry and agriculture by Electric Utilities. A hybrid DC-AC home essentially further promotes the concept of a Green Building / home concept. The growth of Electric Vehicles also gives scope for a back-up supply to ensure lighting in case of emergency. Roof-top solar power adds to social security as massive power failures at Dams / Thermal Plants etc., will not lead to black-outs which existed in the past. It can be viewed as Personal Solar Power for a residential home.

\section{Acknowledgements}

I sincerely thank our Head of the Department of Mechanical Engineering, Dr. Satish Kumar $\mathrm{KM}$, for giving me immense support in helping me to complete the above work. I also wish to thank our Principal, Dr. Mohan Babu G.N and Management of BMS Institute of Technology \& Management for their encouraging gesture shown towards me.

\section{REFERENCES:}

1. W. J . Pellis, "The low voltage house", in Electrtechniek: Technische Uversiteit Endhoven, (1997), p.79

2. M. Friedman, "Concept for a DC low voltage house,' in Sustainable building2002 Conference, 2002, p.6

3. Giovanna Postiglione, 'DC distribution system for home and office,' in Department of Electrical power engineering.vol.MSc Gartenberg, Sweden: Chalmers University of Technology, 2001, p.105

4 .Building Research Establishment, "The use of direct current output from PV systems in buildings', Department of Trade and Industry, London 2002.ETSU S/P2/00373/REP

5. Lasseter, R.and Paigi, P., "Micro grid: A conceptual solution", IEEE Power electronics specialist's conference, IEEE, 2004.

6. Ghareeb, A.T, Mohamed, A., \&Mohammed, O.A,'DC micro grids and distribution systems: An overview", Power and Energy Society General meeting, .IEEE, 2013.

7. Electric Power Research Institute (EPRI), Duke Energy, "DC Powered data Centre demonstration": Executive summary, 2011.

8. Marnay C, "Building scales, building micro grids", 2012.

9. Nordman, B. \& Christensen K, "DC local power distribution: technology, deployment and pathways to success", IEEE Electrification magazine, 2016.

10. Venkat Raja Raman, Ashok Jhunjhunwala, Prabjoth Kaur, Uma Rajesh, "Economic Analysis of deployment of DC power and appliances along with solar in urban multi-storied buildings." CEO, Cygni Energy Pvt Ltd, Hyderabad, India.

11.https://e2e.ti.com/blogs /b/industrial strength/archive/2018/02/06/cut-the-power-andcomplexity-of-your-appliance-designs

12. https://www.bldcmotor.org/energy-saving-bldc-motor-for-household-application.html

APPENDIX A - Typical power requirements in a 2 BHK home (Hybrid DC-AC power) In this appendix typical power requirements of hybrid AC-DC 2BHK home (Fig. A1) are given. A separate bus bar for $\mathrm{AC}$ and $\mathrm{DC}$ are assumed to be set up and with the AC appliances are cantered around the AC bus bar while the DC appliances are connected to the DC bus 
bar. For the available rating of different $\mathrm{AC}$ and Dc appliances, the power required for a typical 2 BHK is shown in Table A1. The actual gain of the hybrid system depends on proper estimation of actual losses in each bus systems and cost of conversion equipment etc.,

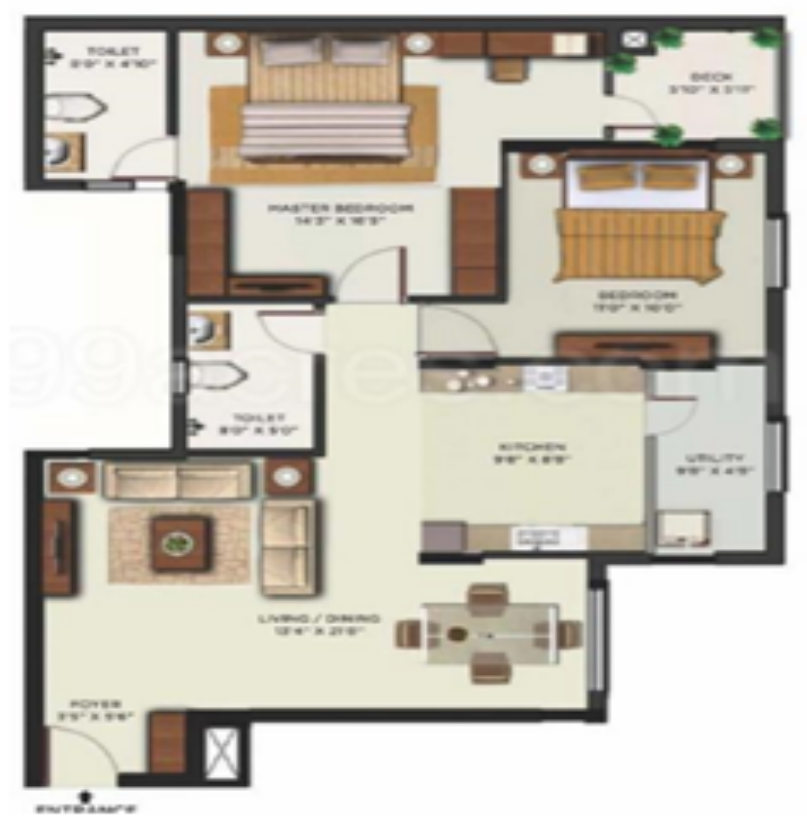

Figure A1: Plan of a typical 2BHK home

\begin{tabular}{|c|c|c|c|c|c|c|}
\hline $\begin{array}{l}\mathrm{S} 1 \\
\mathrm{~N} \\
\mathrm{O}\end{array}$ & $\begin{array}{l}\text { Description of } \\
\text { Appliance }\end{array}$ & Qty & $\begin{array}{l}\text { Average } \\
\text { hours of each } \\
\text { appliance/day }\end{array}$ & $\begin{array}{l}\text { Power } \\
\text { (W) }\end{array}$ & $\begin{array}{l}\text { Energy } \\
\text { consumed/day } \\
(\mathrm{kWh})\end{array}$ & $\begin{array}{l}\text { Energy } \\
\text { consumed/month } \\
(\mathrm{kWh})\end{array}$ \\
\hline \multicolumn{7}{|c|}{ DC Power Units } \\
\hline 1 & Lamp & 6 & 3 & 10 & 0.18 & 5.4 \\
\hline 2 & Tube light & 2 & 4 & 10 & 0.08 & 2.4 \\
\hline 3 & TV & 1 & 8 & 36 & 0.288 & 8.64 \\
\hline 4 & Fan & 4 & 4 & 18 & 0.288 & 8.64 \\
\hline 5 & Computer & 1 & 2 & 24 & 0.048 & \multirow{2}{*}{$\begin{array}{ll} & 1.44 \\
26.52 & \\
\end{array}$} \\
\hline \multicolumn{6}{|c|}{ Total DC power/month } & \\
\hline \multicolumn{7}{|c|}{ AC Power Units } \\
\hline 6 & Refrigerator & 1 & 24 & 19 & 0.456 & 13.68 \\
\hline 7 & Water Geyser & 1 & 1 & 2000 & 2 & 60.00 \\
\hline 8 & $\begin{array}{l}\text { Washing } \\
\text { machine }\end{array}$ & 1 & 1 & 2000 & 2 & 60.00 \\
\hline 9 & Mixer Grinder & 1 & 1 & 600 & 0.6 & 1.80 \\
\hline $\begin{array}{l}1 \\
0\end{array}$ & Pump Motor & 1 & 1 & 740 & 0.74 & 22.00 \\
\hline \multicolumn{7}{|c|}{$\begin{array}{l}\text { Total AC power/month } \\
18\end{array}$} \\
\hline
\end{tabular}

Table A1 : Typical power requirements for various AC and DC appliances 